\title{
Research on the Planning System of Applied Professional Degree Graduate Students' Teaching Materials
}

\author{
Shoujin Wang ${ }^{\mathrm{a}}{ }^{*}$, Junling Liu ${ }^{\mathrm{b}}$ and Huanliang Sun ${ }^{\mathrm{c}}$
}

School of Information and Control engineering, Shenyang Jianzhu University, Shenyang, 110168, China;

a23917240@qq.com, b2428872271@qq.com, '1968207285@qq.com

*The corresponding author

\begin{abstract}
This paper aims at meeting the needs of China's application-oriented talents and achieving high-level application-oriented personnel training objectives. The construction of professional materials is the basis of the cultivation of applied talents. Therefore, to establish a set of high-level application-oriented talents to cultivate professional graduate degree teaching material planning system method, the application of this method can achieve work plan of textbook and guiding the specific textbook preparation. It is of great significance to study the scientific and reasonable professional postgraduate teaching material system. This paper is based on information technology, describing a set of teaching materials planning scheme.
\end{abstract}

Keywords: High level; Applied; Talent cultivation; Professional degree; Textbook planning

\section{应用型专业学位研究生教材规划体系研究}

\author{
王守金 ${ }^{1}$, 刘俊岭 ${ }^{2}$, 孙焕良 \\ ( 沈阳建筑大学 信息与控制工程学院, 辽宁 沈阳 110168)
}

摘要: 为了适应我国对应用型人才的需求, 实现面向高层次应用型人才培养的目标。专业学位的教材建设是应用型人 才培养的基础, 因此, 建立一整套面向高层次应用型人才培养的专业学位研究生教材规划体系方法, 应用该方法可以实现对 教材的规划工作, 并可以实现对某一具体教材的编写进行指导。研究科学合理的专业学位研究生教材体系具有重要的意义, 本文以计算机技术学科为例, 给出一整套教材规划方案。

关键词：高层次；应用型；人才培养；专业学位；教材规划

中图分类号：G643.0 文献标志码：A

引言

据调查, 欧美高校毕业生中 $80 \%$ 是应用型人才, $20 \%$ 是学术型人才, 而我国高校毕业生人才比例 $40 \%$ 是 应用型人才, $60 \%$ 为学术型人才 $[1]$ 。我国实际并不需要如此多的学术型人才。教育部 2012 年全国高校毕 业生就业率排名给予了统计数据的支撑, 据统计, 就业率排在第一位的是 985 高校, 第二位是高职院校, 第三位是 211 大学, 第四位是独立学院, 第五位是科研院所, 第六位是地方普通高校。从这个结果发现, 应用型人才有较少的需求量。

教育部 2014 年度工作要点明确提出, 要引导一批本科高校向应用技术类高校转型, 以适应我国对应用 型人才的需求。当年, 国务院印发《关于加快发展现代职业教育的决定》, 明确了建立以职业需求为导向、 以实践能力培养为重点、以产学结合为途径的专业学位研究生培养模式的目标。专业学位研究生培养针对 高层次应用型人才需求, 是本科应用人才的延伸。专业学位的教材建设是研究生培养的基础, 研究科学合 
理的专业学位研究生教材体系具有重要的意义 [2]。

本文研究面向高层次应用型人才培养的专业学位研究生教材规划体系, 指导规划教材的编写, 并针对 计算机技术专业学位, 选择一些核心课程进行教材编写, 并应用这些教材总结分析效果, 提高毕业研究生 的实践能力, 为教学发挥基础性作用, 助力教学改革。

\section{1 国内外相关研究}

现有的各专业的教材规划以学科知识点为依据, 存在以下两个方面的问题: 首先, 学科知识点按课程 划分, 粒度较大, 课程内部的知识点相对独立, 课程间的联系不够紧密。其次, 应用实践类的内容不够系 统, 大多以知识为主导, 不是以行业需求为主导, 体现为对某门课程进行实践。下面以计算机技术学科为 例分析现有教材体系存在的问题。

\section{1 国外研究综述}

国外与计算机学科教育相关的协会发展较为完善, 学会定期发布的教材规划指导文件都是对计算机学 科教材规划研究最新成果的总结和概括。从这些国外教育协会发布的相关教材规划报告中, 可以粗略了解 国外在计算机研究生教材规划研究方面的大体情况和相关进展。

美国计算机学会 (ACM) 与美国电气和电子工程师协会下属的计算机学会一直致力于对计算机学科的教 育问题进行深入且系统的研究并发布各种计算机教育指导文件。1989 年, ACM 发布了《计算作为一门学科》 报告, 该报告中针对计算机学科教材规划提出了二个重要问题, 计算学科核心教材规划如何设置。

此外，对国外计算机技术专业学位研究生教材规划产生较大影响的还有美国工程技术认证协会 (ABET) 制定的相关认证标准。该标准对国外高校整个工程教育起到重要的约束作用。Lisa R. Lattuca 等总结了 $\mathrm{EC}$ 对现代计算机工程师的要求包括: “工程实践能力、是多学科的工学背景以及工程设计方面的能力、职 业道德以及社会责任感”, 这也就要求计算机专业学位研究生教材规划中应加强实践教材规划和工程伦理 教材规划的设置。

\section{2 国内研究综述}

目前，国内直接对计算机技术专业学位研究生教材规划进行的研究数量较少，对于计算机技术专业学 位研究生教材规划的研究整体较为薄弱。与本研究关联较为密切的还有对计算机学术型研究生教材规划进 行的研究, 该类研究的相关成果对计算机技术专业学位研究生教材规划具有一定的指导作用。在研究方法 上，上述所有的研究都是采用了定性和思辨的方法，缺少问卷调查的实证支撑。

岳昆等从教材定位、教学内容和教学方法等方面对计算机专业硕士研究生教材规划进行探索与实践, 得出计算机技术专业学位研究生教材应具有应用性、前瞻性、实践性和综合性 [3]。强保华等探讨了计算 机技术专业学位研究生教材规划的多个环节, 对教材规划中的相关问题缺少进一步的归因和分析 [4]。王 士同等对计算机学科学术型硕士与专业学位研究生进行了相关对比, 并对计算机技术专业学位研究生的教 材规划提出了建议 [5]。李爱平等分析了计算机技术专业学位研究生在真实软件开发项目中的能力增长方 式, 其相关成果可以为本文中实践教材规划环节的研究提供参考 [6]。叶东毅和余春艳等对计算机学术型 研究生教材规划中应用能力和工程能力的提高方式进行了研究 [7]。虽然计算机技术专业学位研究生与学 术型硕士相比, 教材规划理念与目标都有所不同, 但由于二者在教材规划的诸多方面还是有很多共性之处, 因此对本研究中的诸多探索都起到理论奠基的作用。 
此外, 一些国内学者对国外计算机研究生教材规划进行了研究。这类研究有助于本文中更好的发现国 内计算机专业学位研究生教材规划中的问题并借鉴国外教材规划的优势做法。

\section{2 研究内容}

\section{1 应用型专业学位研究生教材体系建立方法学研究}

现有的教材大多针对全日制学术型硕士研究生的培养, 面向应用的培养模式才刚刚起步, 与发达国家 相比尚缺乏很多经验, 因此关于如何做好专业学位硕士教材体系仍需进行深入研究和实践。面向高层次应 用型人才培养的专业学位研究生教材体系建立方法是本文首要的研究内容。针对这一问题, 本文以计算机 技术专业学位为试点, 以培养质量保障体系的建立为重点, 专门研究符合 “应用型” 特色的教材体系构建。

\section{2 研究如何将专业硕士实践教学在教材中充分体现}

面向应用的专业学位硕士必须有至少一年的实践教学时间，这是培养全日制专业学位硕士专业技能、 实践能力的关键环节。然而，这一环节目前还存在实践基地贵乏、双导师制责任不够明确以及审核不够严 格等诸多问题。因此, 在教材体体系的建立方面, 需充分体现实践技能的培养。针对这一问题, 本文着重 研究如何将实践教学环节映射到教材中的方面, 通过对应用技能的调研, 收集整理实践知识点, 并系统地 将这些实践技能渗透到教材中。并结合工程实践基地建设，实验课程教材作为学科教材的有效补充。

\section{3 研究应用型专业学位研究生教材体系的评价方法}

教材的应用情况如何，需要进行有效评价发现问题，从而进行调整。本文将通过培养实践，将具有工 程背景的专家、管理人员、学生组成评价组, 对教材体系、单个教材进行评价, 建立合理的评价指标体系。 建立评价的反馈机制，从而更好地指导教材建设。

\section{3 具体研究实施方案}

通过调研、查阅资料、拟定教材规划的方法，研究教材体系方案，拟采用的具体研究实施方案如图 1 所示。

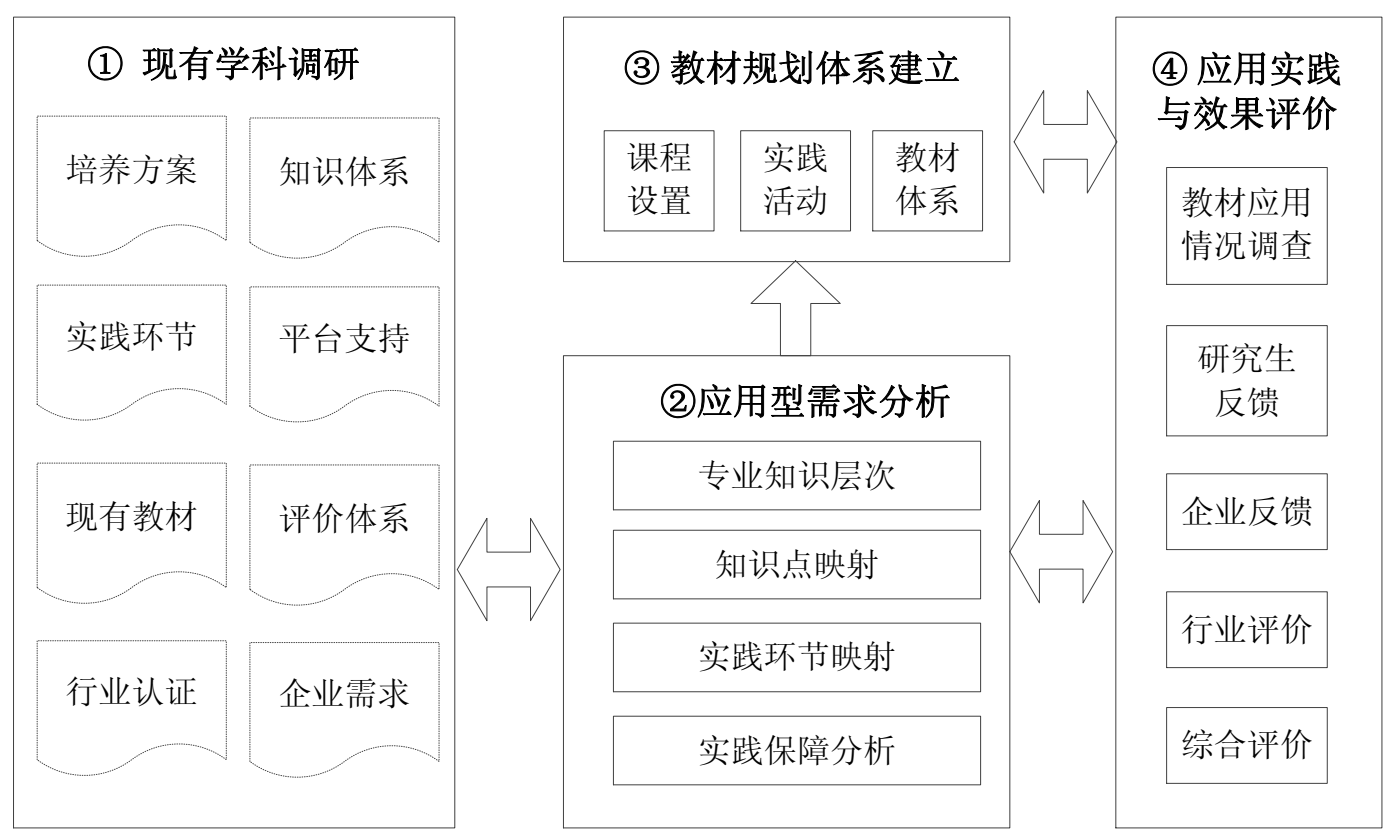

图1 研究实施方案图

第一步为学科调研工作，主要通过围绕境内和境外两大部分展开，境内以走访 211、985 院校为主, 
境外主要通过科研合作伙伴、同学和学生, 在相关学科著名大学进行联系, 调研的内容包括学科培养方案、 知识体系、实践环节、现有教材、行业认证、企业需求等。

第二步工作为应用需求分析，主要在调研分析的基础上，拟定适合 “应用型” 专业硕士的培养方案。 在培养方案中, 对课程结构进行详细说明, 强调实践教学的内容和考核方法, 在此基础上将知识点分层次 分布到教材中。通过组建培养专业硕士的人才培养基地, 实际工程项目培养 “应用型” 高级技术人才。

第三步具体建立教材体系, 将分解的实践知识应用到教材的编写中, 本部分要结合现有的教材体系, 将教材分类了传统的知识型、实践型及特色专业型, 其中特色专业型更新较快, 建立教材指导规划时要注 意实践内容的更新。

第四步是应用实践与效果评价。通过实践建立教材质量评价体系，该体系要结合专业学位硕士质量、 企业评价、人才质量等因素。加入以企业为导向的质量保障措施，使得培养的应用型人才更贴合企业的需 求为保证专业硕士的培养质量奠定基础保障。评价指标重点考查教材中实验部分的效果。

\section{5 结论}

通过对国内外应用型专业硕士研究生教材的现状开展调研、测评论证分析，明确我国目前在教材建设 上的不足，有选择地借鉴国内外高校在教材方面的经验。通过对面向高层次应用型人才培养的专业学位研 究生教材体系建立方法学以及教材体系的评价方法的研究, 确定初步的教材规划方法论, 设计应用实验点 方案、构建培养质量的保障体系。以计算机技术学科为例, 建立教材规划体系, 明确教材中实践教学环节 和实践基地保障措施。

\section{6 致谢}

基金项目：2016-2017 年全国工程专业学位研究生教育自选研究课题（2016-ZX-127); 辽宁省社会科学规划基金 (L15BGL017)

\section{Acknowledgement}

Fund project: 2016-2017 national engineering professional degree graduate education customize research project (2016 - ZX - 127); Liaoning province social science fund plan (L15BGL017)

\section{参考文献:}

[1] 研究生教育质量报告编研组。中国研究生教育质量年度报告（2014），中国科学技术出版社，2015, 北京.

[2] 中国学位与研究生教育发展年度报告课题组. 中国学位与研究生教育发展年度报告 2013, 中国人民大学出版社, 2014, 北京.

[3] 岳昆, 蒋慕蓉, 张学杰。计算机技术” 全日制工程硕士专业课建设的新思路一一 “数据工程” 课程为例。云南大 学学报: 自然科学版, 2011 年, 第 S2 期。

[4] 强保华, 陶林, 汪天天, 何倩, 夏芳。计算机科学与技术全口制专业学位研究生教材规划体系设置研究, 计算机光 盘软件与应用, 2012，(8)。

[5] 王士同, 李岳阳, 陆健雄。关于计算机科学与技术专业工学硕士和专业学位研究生课程教学和课程体系的思考, 无 锡教育学院学报, 2004, 24 (2)。

６］李爱平, 丁红利, 朱福喜。从实战中培养工程硕士开发大型软件项目的能力, 计算机教育, 2011，(14）:1-3。

[7] 叶东毅, 余春艳. 学术型计算机专业硕士研究生工程能力培养研究. 计算机教育. 2012 (04)。 


\section{References}

[1] A graduate student studying education quality report group. China's postgraduate education quality of the annual report (2014), China science and technology press, 2015, Beijing.

[2] The China academic degrees and graduate education development of the annual report group. The China academic degrees and graduate education development of the annual report 2013, the Chinese people's university press, 2014, Beijing.

[3] YueKun, Jiang Murong, Zhang xue-jie. Computer technology "full-time master of engineering specialized course of the construction of the new way of thinking - in" data construction "course as an example. Journal of yunnan university: natural science edition, 2011, the first S2.

[4] Qiang Baohua, TaoLin, Wang Tiantian. System of computer science and technology with complete professional degree graduate student teaching material planning system is set research, computer cd-rom software and applications, 2012, (8).

[5] Wang Shitong, Li Yueyang, Liu Jianxiong. About computer science and technology professional master degree and specialized degree graduate student curriculum teaching and course system of thinking, journal of wuxi institute of education, 2004, 24 (2).

[6] Li Aiping, Ding Gongli, Zhu Fuxi. From the actual combat training engineering master's ability to develop large-scale software projects, computer education, 2011, (14): 1-3.

[7] Ye Dongyi, YuChunyan. Academic master's degree in computer engineering ability training research. Computer education. 2012 (04). 